\title{
Bilateral pulmonary arterial banding results in an increased need for subsequent pulmonary artery interventions
}

\author{
Ryan R. Davies, MD, ${ }^{\mathrm{a}, \mathrm{b}}$ Wolfgang A. Radtke, MD, ${ }^{\mathrm{a}, \mathrm{b}}$ Dore Klenk, CRT-NPS, ${ }^{\mathrm{a}}$ and Christian Pizarro, MD ${ }^{\mathrm{a}, \mathrm{b}}$
}

Objective: Despite increasing use of bilateral branch pulmonary artery banding (bPAB), both as a temporary stabilizing treatment and as part of comprehensive hybrid management of hypoplastic left heart syndrome, little is known about the long-term outcomes of the pulmonary arteries (PAs) in banded patients.

\begin{abstract}
Patients and Methods: We conducted a retrospective review of all patients with ductal-dependent systemic circulation (2001-2013) undergoing bPAB placement at a single institution (bPAB, $\mathrm{n}=50$ ); patients who underwent a stage I Norwood procedure (Norwood, $\mathrm{n}=53$ ) were used for comparison. The need for PA interventions (surgical arterioplasty, balloon angioplasty, and stent implantation) and PA growth were assessed.

Results: Bands were in place for a median of 76 days. PA growth and size were similar between groups, but bPAB patients required more interventions $(1.4 \pm 2.9$ vs $0.5 \pm 1.2, P=.01)$. In competing risks analysis, only $20 \%$ of bPAB patients were alive and free from intervention at 5 years after bPAB removal. Multivariable Cox proportional hazards regression of operative interventions within the bPAB group demonstrated the following risk factors: subsequent 2-ventricle repairs (hazard ratio [HR], 2.2; 95\% confidence interval [CI], 0.7-6.7), smallest band diameter (HR per additional millimeter, 0.059; 95\% CI, 0.004-0.849), and duration of band placement more than 90 days (HR, 3.5; 95\% CI, 1.0-12.6). Hemodynamics and Fontan candidacy did not differ between groups.
\end{abstract}

Conclusions: Patients with bPAB require additional interventions at earlier time points than Norwood patients. Patients with smaller bands and longer duration of banding are at high risk. Despite stenoses requiring additional interventions, Fontan candidacy is maintained. (J Thorac Cardiovasc Surg 2014;147:706-12)

Bilateral branch pulmonary arterial banding (bPAB) is an attractive method for control of pulmonary blood flow in ductal-dependent lesions. It is performed both as part of a comprehensive strategy for hybrid palliation and to stabilize patients in the immediate postnatal period with pulmonary overcirculation and ductal-dependent blood flow. ${ }^{1-4}$ Pulmonary arterial banding has important consequences on the vascular wall that may result in important longterm consequences to pulmonary arterial growth potential. ${ }^{1-6}$ Patients with hypoplastic left heart syndrome undergoing a comprehensive stage 2 procedure have an increased need for pulmonary artery interventions. ${ }^{3,6}$ Whether this is a consequence of the stage 2 operation or attributable to the bPABs and whether particular patients might be at high risk for pulmonary arterial stenosis and growth impairment have not been investigated.

\footnotetext{
From Nemours Cardiac Center, ${ }^{a}$ Nemours/A.I. duPont Hospital for Children, Wilmington, Del; and Thomas Jefferson University, ${ }^{\mathrm{b}}$ Philadelphia, Pa.

Disclosures: Authors have nothing to disclose with regard to commercial support.

Read at the 39th Annual Meeting of The Western Thoracic Surgical Association, Coeur d'Alene, Idaho, June 26-29, 2013.

Received for publication July 6, 2013; revisions received Sept 27, 2013; accepted for publication Oct 11, 2013; available ahead of print Nov 25, 2013.

Address for reprints: Ryan R. Davies, MD, Nemours/A.I. duPont Hospital for Children, 1600 Rockland Rd, Wilmington, DE 19803 (E-mail: rdavies@ nemours.org). $0022-5223 / \$ 36.00$

Copyright (c) 2014 by The American Association for Thoracic Surgery

http://dx.doi.org/10.1016/j.jtcvs.2013.10.038
}

At our institution, bPAB has been used both as part of a comprehensive hybrid management strategy and for immediate stabilization in both single-ventricle and 2-ventricle patients with ductal-dependent lesions. We undertook a review of all patients undergoing bPAB placement to evaluate the impact of bPAB on the long-term outcomes of the pulmonary artery (PA), identify risk factors for poor outcomes, and suggest strategies to mitigate the negative impact of bPABs.

\section{METHODS \\ Patient Population}

We performed a retrospective review of all patients undergoing bPAB at a single institution (bPAB, $n=50)$. These patients were compared with a contemporaneous group of patients undergoing stage 1 Norwood palliation (Norwood, $\mathrm{n}=54$ ). Diagnoses and birth history are shown in Table 1. Overall median follow-up was 32.9 months (intraquartile range [IQR], 4.3-69.6). The Nemours Institutional Review Board approved the study.

\section{Surgical and Interventional Procedure Performed \\ During this time period, patients underwent either bPAB or standard surgical palliation based on preoperative condition and physician prefer- ence. Technical details of patients undergoing bPAB have been reported previously. ${ }^{7}$ In summary, bPABs of polytetrafluoroethylene were placed without cardiopulmonary bypass and typically over a $2.5-\mathrm{mm}$ probe. Band tightness was adjusted to maintain systemic oxygen saturation in the $80 \%$ to $85 \%$ range. In selected patients, bPABs were placed before either ductal stenting, stage 1 Norwood palliation, or definitive 2- ventricle repair to stabilize patients with excessive pulmonary artery blood}




$$
\begin{aligned}
& \text { Abbreviations and Acronyms } \\
& \text { BDG }=\text { bidirectional Glenn } \\
& \text { bPAB }=\text { branch pulmonary arterial banding } \\
& \mathrm{CI}=\text { confidence interval } \\
& \mathrm{HR}=\text { hazard ratio } \\
& \mathrm{IQR}=\text { intraquartile range } \\
& \mathrm{OR}=\text { odds ratio } \\
& \mathrm{PA} \quad=\text { pulmonary artery }
\end{aligned}
$$

flow and/or maldistribution of cardiac output. Modified stage 1 Norwood palliation was performed using deep hypothermic circulatory arrest; pulmonary blood flow was provided by either a right ventricle (RV)-pulmonary artery (PA) conduit or a modified Blalock-Taussig shunt.

Superior cavopulmonary connections were usually performed using a hemi-Fontan connection constructed of pulmonary homograft. Bidirectional Glenn (BDG) anastomoses were used at the surgeon's discretion.

\section{Hemodynamics and Measurements of Pulmonary Arterial Size and Growth}

Diagnostic catheterizations for all patients were reviewed. Branch PA size was reported as the smallest diameter within that branch before hilar branching. Sizes are reported both as raw data and indexed to patient body surface area. Growth was measured as the difference between the first and last measured size among patients with size measurements at least 6 months apart divided by the elapsed time. When calculating growth rates, interval interventions were ignored. Hemodynamic measurements were obtained from catheterization reports. Mean PA pressures are reported and are the lowest reported pressures within the main and branch PAs proximal to any significant stenoses with the branch PAs. Prestage 2 and preFontan data were defined as the last catheterization containing the relevant measurement before performance of the respective surgery.

\section{Operative and Catheter-Based Interventions}

Operative interventions were defined as any surgical procedure involving an attempt to address branch PA stenosis: patch arterioplasty, excision and reconstruction of a pulmonary artery segment, rigid or balloon dilation, or placement of a stent via an open surgical procedure. Because the hemi-Fontan was performed routinely, this was not included as an operative intervention on the PAs (nor was placement of a BDG anastomosis). Catheter-based interventions were limited to either balloon angioplasty or stent placement in the PA. Interventions directed at other lesions (eg, recoarctation) were not included. Patients requiring more than 1 intervention on separate dates were considered to have undergone multiple interventions.

\section{Statistical Analysis}

Statistical analysis was conducted using SAS 9.2 for AIX (SAS Institute Inc, Cary, NC). Statistical tests used to identify predictors of outcomes included the $\chi^{2}$-test and the paired $t$ test. Duration of bPAB placement was analyzed both as a continuous variable and stratified into 3 groups: 14 or less days, 14 to 90 days, and more than 90 days. Time-to-event outcomes were assessed with Kaplan-Meier survival estimates (log-rank rest for difference between strata, $P<.05$ ). Multivariate regression of binary outcomes was performed using logistic regression (backward selection, $P<.2$ to remain). Cox proportional hazards regression was used to identify risk-adjusted models for time-to-event analyses (backward selection, $P<.2$ to remain). Competing risks analysis was performed using the cmprisk package of $\mathrm{R}$ for Windows.

\section{RESULTS}

Baseline demographics, birth history, and preoperative clinical condition for Norwood and bPAB patients are shown in Table 1. Median follow-up was longer among the Norwood patients (51.3 months [IQR, 16.2-82.5 months] vs bPAB:10.9 months [3.3-46.7 months], $P=.01$ ).

Median bPAB diameter was $2.5 \mathrm{~mm}$ for both right and left PA (range, 2.0-3.5 mm). Ductal stenting was performed during the same procedure as bPAB in 14 patients $(28.0 \%)$, and an additional 17 patients $(62.0 \%)$ had insertion of a ductal stent as a separate procedure. When performed as a separate procedure, the ductal stent was placed a median of 6.5 days (IQR, 4-11) after bPAB.

Adjustment of band diameter was necessary in 8 patients $(16.0 \%)$ at a median of 6.5 days (IQR, $0-24$ days) after band placement. Bands were in place for a median of 76 days (IQR, 18-103 days) before either removal or patient death. There was a trend toward higher in-hospital mortality among the bPAB patients (Norwood, 13.0\%; bPAB, $26.0 \% ; P=.09$ ).

Superior cavopulmonary connections were created in 56 patients at a median of 5.4 months of age (IQR, 4.4-6.7 months). The Fontan procedure was performed in 34 patients at a median of 18.3 months (IQR, 14.723.5 months). Creation of a superior cavopulmonary anastomosis was more common among the Norwood patients $(64.9 \%$ vs $42.0 \% ; P=.02)$, and there was a trend toward a higher incidence of eventual Fontan palliation among Norwood patients $(38.9 \%$ vs $26.0 \% ; P=$ not significant [NS]). Two-ventricle repairs were performed in 17 patients at a median of 3.8 months of age (IQR, 2.1-5.8 months). A higher proportion of $\mathrm{bPAB}$ patients ultimately underwent a 2 -ventricle repair $(26.0 \%$ vs $7.4 \% ; P=.01)$. Heart transplant was performed in 1 patient after a Norwood procedure and in 2 patients after $\mathrm{bPAB}$.

\section{Pulmonary Arterial Growth and Size}

Right and left pulmonary arterial size (both raw and indexed to body surface area) did not differ significantly between groups at any defined time during follow-up (Table 2). Left pulmonary arterial growth was $1.3 \pm 1.5 \mathrm{~mm} / \mathrm{y}$ in Norwood patients and $0.6 \pm 1.5 \mathrm{~mm} / \mathrm{y}$ $(P=.15)$. Indexed growth measurements in the left PA were $4.7 \pm 4.3 \mathrm{~mm} / \mathrm{y} / \mathrm{m}^{2}$ in the Norwood patients and $1.7 \pm 10.9 \mathrm{~mm} / \mathrm{y} / \mathrm{m}^{2}$ in the $\mathrm{bPAB}$ patients $(P=.3)$. Right PA growth was also not different between groups, either nonindexed (Norwood: $1.7 \pm 4.7 \mathrm{~mm} / \mathrm{y}$ vs bPAB $3.7 \pm 5.2 \mathrm{~mm} / \mathrm{y} ; P=.2$ ) or indexed (Norwood $2.5 \pm 1.5 \mathrm{~mm} / \mathrm{y} / \mathrm{m}^{2}$ vs bPAB $3.3 \pm 1.9 \mathrm{~mm} / \mathrm{y} / \mathrm{m}^{2}$; $P=.3$ ). Left and right PA size and band removal and subsequent PA growth did not differ between patients undergoing single- versus 2-ventricle repairs.

Obliteration of a branch PA occurred in 2 Norwood patients and $1 \mathrm{bPAB}$ patient $(P=\mathrm{NS})$. Obliteration of a 
TABLE 1. Baseline demographics and clinical variables among patients undergoing bilateral pulmonary arterial banding (bPAB) or stage 1 Norwood palliation

\begin{tabular}{|c|c|c|c|}
\hline & $\begin{array}{c}\text { Norwood } \\
(n=54)\end{array}$ & $\begin{array}{c}\text { bPAB } \\
(\mathbf{n}=\mathbf{5 0})\end{array}$ & $\begin{array}{c}P \\
\text { value }\end{array}$ \\
\hline Age $(\mathrm{d}$, mean $\pm \mathrm{SD})$ & $13.8 \pm 27.9$ & $8.6 \pm 10.1$ & NS \\
\hline Weight $(\mathrm{kg}$, mean $\pm \mathrm{SD})$ & $3.3 \pm 0.6$ & $2.6 \pm 0.7$ & $<.0001$ \\
\hline Gestational age (wk, mean \pm SD) & $38.4 \pm 1.6$ & $36.5 \pm 2.9$ & .0004 \\
\hline Birth weight $(\mathrm{kg}$, mean $\pm \mathrm{SD})$ & $3.2 \pm 0.6$ & $2.5 \pm 0.7$ & $<.0001$ \\
\hline Gender (male), n (\%) & $29(53.7)$ & $33(66.0)$ & NS \\
\hline Genetic syndrome, $\mathrm{n}(\%)$ & $4(8.3)$ & $9(20.0)$ & .1 \\
\hline $\begin{array}{l}\text { Noncardiac congenital abnormality, } \\
\mathrm{n}(\%)\end{array}$ & $5(13.5)$ & $7(26.9)$ & NS \\
\hline Premature, $\mathrm{n}(\%)$ & $5(10.4)$ & $14(30.4)$ & .016 \\
\hline \multicolumn{4}{|l|}{ Diagnosis, $\mathrm{n}(\%)$} \\
\hline Hypoplastic left heart syndrome & $32(59.3)$ & $25(50.0)$ & NS \\
\hline Atrioventricular septal defect & $5(9.3)$ & $5(10.0)$ & NS \\
\hline Interrupted aortic arch & $4(7.4)$ & $3(6.0)$ & NS \\
\hline Transposition of the great arteries & $2(3.7)$ & $2(4.0)$ & NS \\
\hline Double-outlet right ventricle & $4(7.4)$ & $3(6.0)$ & NS \\
\hline Truncus arteriosus & $0(0.0)$ & $3(6.0)$ & .06 \\
\hline Ebstein anomaly & $0(0.0)$ & $1(2.0)$ & NS \\
\hline Mitral atresia & $15(27.8)$ & $14(28.0)$ & NS \\
\hline Aortic atresia & $22(40.7)$ & $18(36.0)$ & NS \\
\hline \multicolumn{4}{|l|}{ Preoperative variables, n (\%) } \\
\hline Mechanical ventilation & $3(5.9)$ & $28(56.0)$ & $<.0001$ \\
\hline $\begin{array}{l}\text { Extracorporeal membrane } \\
\text { oxygenation }\end{array}$ & $1(2.0)$ & $2(4.0)$ & NS \\
\hline Ventricular dysfunction & $2(4.7)$ & $14(29.2)$ & .002 \\
\hline $\begin{array}{l}\text { Atrioventricular valve regurgitation } \\
\text { moderate or higher }\end{array}$ & $4(9.8)$ & $7(14.3)$ & NS \\
\hline Preoperative shock & $3(6.1)$ & $12(26.1)$ & .008 \\
\hline \multicolumn{4}{|l|}{ Operative variables } \\
\hline $\begin{array}{l}\text { Cardiopulmonary bypass time } \\
\quad(\text { min, mean } \pm \mathrm{SD})\end{array}$ & $143 \pm 56$ & N/A & \\
\hline DHCA time (min, mean \pm SD) & $57 \pm 21.4$ & N/A & \\
\hline
\end{tabular}

$S D$, Standard deviation; $N / A$, not available.

lobar branch occurred in 4 Norwood patients $(7.4 \%)$ and 6 bPAB patients $(12.0 \% ; P=\mathrm{NS})$.

\section{Pulmonary Arterial Interventions}

A total of 335 catheterizations were performed. Balloon angioplasty of the left PA was performed in 26 catheterizations (Norwood, 2; bPAB, 24) and of the right PA in 17 catheterizations (Norwood, 4; bPAB, 13). Stent implantation occurred in the left PA in 14 catheterizations (Norwood, 3 ; $\mathrm{bPAB}, 11)$ and in the right $\mathrm{PA}$ in 3 catheterizations (bPAB, 3).

The percentage of patients requiring any catheter-based intervention was similar between the groups (Norwood, 8 [14.8\%]; bPAB, $12[24.0 \%] ; P=.2)$, but patients in the $\mathrm{bPAB}$ group required a greater number of diagnostic and interventional catheterizations during follow-up (Figure 1). The need for multiple pulmonary arterial interventions was higher among the bPAB group (11 of $50,22.0 \%$ vs 4 of $54,7.4 \%, P=.03)$. Intervention-free survival was worse among the pPAB group (Figure 2). Competing risks analysis demonstrates that at 5 years only $20 \%$ of bPAB patients remain alive and free from intervention, compared with $51 \%$ of Norwood patients (Figure $3 ; P=.057$ ).

Among all patients, those ultimately undergoing 2-ventricle repairs had a higher incidence of requiring interventional catheterizations $(47.1 \%$ vs $13.8 \% ; P=.0015)$. The timing of interventions was evenly distributed between before, concurrent with, and after the 2-ventricle repair. The need for PA interventions was more common on both the right PA (2-ventricle, 6 of 17 [35.3\%] vs 1-ventricle, 6 of $87[6.9 \%] ; P=.0008)$ and the left PA (2-ventricle, 6 of 17 [35.3\%] vs 1 -ventricle 8 of 87 [9.2\%]; $P=.004$ ). The risk of multiple interventions was higher in the 2-ventricle patients in both the right PA $(11.8 \%$ vs $1.2 \% ; P=.01)$ and left PA $(29.4 \%$ vs $3.5 \%, P=.0002)$.

\section{Risk of Multiple Pulmonary Arterial Interventions Among bPAB Patients}

Preoperative factors (including patient age at bPAB placement, gestational age, and birthweight) did not predict the need for multiple PA interventions. Patients requiring subsequent adjustment of bPAB diameter or position did not have a significantly higher risk of multiple reinterventions (no adjustment, $12.5 \%$ vs adjusted, $23.8 \%$; $P=\mathrm{NS}$ ). The tightening of left and right bands to different diameters also did not result in a significant increase in the incidence of multiple reinterventions (identical diameter, $16.7 \%$ vs nonidentical diameter, $23.7 \% ; P=\mathrm{NS}$ ). There was a trend toward longer duration of band placement in patients requiring multiple $\mathrm{PA}$ interventions ( $103 \pm 65$ days vs $65 \pm 53$ days; $P=.06$ ), and patients banded for more than 90 days had a higher incidence of multiple PA interventions $(36.8 \%$ vs $12.9 \% ; P=.047)$. Patients who subsequently underwent a 2-ventricle repair after $\mathrm{bPAB}$ had a higher incidence of requiring multiple PA interventions $(46.2 \%$ vs $13.5 \% ; P=.01)$. Multiple interventions on the left PA were particularly common in the 2-ventricle patients (38.5\% vs $8.1 \% ; P=.01)$; although multiple interventions on the right PA were similar regardless of the number of ventricles (2 ventricles, $7.7 \%$; 1 ventricle, $2.7 \%$; $P=\mathrm{NS})$. Use of comprehensive stage1/stage 2 versus separate stage 1 and stage 2 procedures among the singleventricle $\mathrm{bPAB}$ patients was not associated with an increased need for multiple PA interventions $(20.0 \%$ comprehensive vs $11.1 \% ; P=\mathrm{NS}$ ).

\section{Freedom From Intervention}

In univariate analysis, none of the preoperative or intraoperative risk factors were significant predictors of freedom from catheter or operative interventions. Multivariable Cox proportional hazards regression of operative interventions within the $\mathrm{bPAB}$ group demonstrated the following risk 
TABLE 2. Left and right mean pulmonary artery size measurements

\begin{tabular}{|c|c|c|c|}
\hline & Norwood & bPAB & $P$ value \\
\hline \multicolumn{4}{|l|}{ After bPAB removal or Norwood $*(n=60)$} \\
\hline Left PA $(\mathrm{mm}) / \mathrm{left}$ PA index $\left(\mathrm{mm} / \mathrm{m}^{2}\right)$ & $3.8 \pm 1.9 / 11.6 \pm 5.1$ & $4.2 \pm 3.3 / 12.4 \pm 7.6$ & NS/NS \\
\hline Right PA $(\mathrm{mm}) /$ right PA index $\left(\mathrm{mm} / \mathrm{m}^{2}\right)$ & $4.7 \pm 3.9 / 14.8 \pm 5.5$ & $5.6 \pm 3.8 / 14.5 \pm 6.3$ & NS/NS \\
\hline \multicolumn{4}{|l|}{ Prestage $2(n=29)$} \\
\hline Left PA (mm)/left PA index $\left(\mathrm{mm} / \mathrm{m}^{2}\right)$ & $3.9 \pm 3.2 / 11.5 \pm 3.9$ & $3.5 \pm 2.4 / 14.0 \pm 5.2$ & NS/.06 \\
\hline Right PA $(\mathrm{mm}) /$ right PA index $\left(\mathrm{mm} / \mathrm{m}^{2}\right)$ & $5.0 \pm 1.7 / 15.6 \pm 5.0$ & $3.9 \pm 0.6 / 15.1 \pm 5.6$ & $.04 / \mathrm{NS}$ \\
\hline \multicolumn{4}{|l|}{ Pre-Fontan $(n=22)$} \\
\hline Left PA (mm)/left PA index $\left(\mathrm{mm} / \mathrm{m}^{2}\right)$ & $4.2 \pm 3.3 / 8.7 \pm 2.9$ & $4.3 \pm 3.0 / 12.1 \pm 5.1$ & $\mathrm{NS} / .07$ \\
\hline Right PA $(\mathrm{mm}) /$ right PA index $\left(\mathrm{mm} / \mathrm{m}^{2}\right)$ & $8.0 \pm 1.8 / 16.8 \pm 3.3$ & $6.9 \pm 1.5 / 16.1 \pm 1.8$ & $.14 / \mathrm{NS}$ \\
\hline \multicolumn{4}{|l|}{ Pre-2-ventricle repair $(\mathrm{n}=5)$} \\
\hline Left PA (mm)/left PA index $\left(\mathrm{mm} / \mathrm{m}^{2}\right)$ & $4.2 \pm 2.3 / 13.7 \pm 8.0$ & $3.6 \pm 2.5 / 10.8 \pm 9.6$ & NS/NS \\
\hline Right PA $(\mathrm{mm}) /$ right PA index $\left(\mathrm{mm} / \mathrm{m}^{2}\right)$ & $2.5 \pm 2.1 / 8.1 \pm 6.8$ & $4.0 \pm 1.7 / 10.9 \pm 2.7$ & NS/NS \\
\hline \multicolumn{4}{|l|}{ Final measurement } \\
\hline Left PA (mm)/left PA index $\left(\mathrm{mm} / \mathrm{m}^{2}\right)$ & $5.3 \pm 4.9 / 15.7 \pm 5.1$ & $4.9 \pm 1.7 / 16.8 \pm 5.7$ & $\mathrm{NS} / \mathrm{NS}$ \\
\hline Right PA $(\mathrm{mm}) /$ right PA index $\left(\mathrm{mm} / \mathrm{m}^{2}\right)$ & $7.7 \pm 3.3 / 15.7 \pm 5.1$ & $8.2 \pm 4.5 / 16.7 \pm 6.0$ & NS/NS \\
\hline
\end{tabular}

bPAB, Bilateral pulmonary arterial banding; $P A$, pulmonary artery; $N S$, not significant. *For bPAB patients, the first size measurement is after bPAB removal; for Norwood patients, it is after the Norwood procedure.

factors: subsequent 2-ventricle repairs (hazard ratio [HR], 2.2; 95\% confidence interval [CI], 0.7-6.7), smallest band diameter (HR per additional millimeter, 0.059; 95\% CI, 0.004-0.849), and duration of band placement for more than 90 days (HR, 3.5; 95\% CI, 1.0-12.6). Risk factors were the same for both catheter-based interventions and any intervention. Gestational age and birthweight did not predict freedom from interventions in multivariable analysis.

Multivariable analysis of all patients identified the use of bPABs (HR, 3.8; 95\% CI, 1.5-9.6) and a diagnosis of interrupted aortic arch (HR, 3.8; 95\% CI, 1.3-11.5) as predictive of earlier risk of operative intervention. Gestational age, birthweight, genetic syndromes, and other diagnoses were not predictive of operative interventions.

\section{Hemodynamics}

The ratio of pulmonary vascular resistance to systemic resistance was not different between PA band and non-PA band patients at the prestage 2 catheterization (Norwood, $0.13 \pm 0.11$; bPAB, $0.13 \pm 0.12 ; P=\mathrm{NS}$ ) or at the preFontan catheterization (Norwood, $0.13 \pm 0.03$; bPAB, $0.15 \pm 0.03 ; P=\mathrm{NS})$. PA pressures were also similar at both prestage 2 (Norwood, $12.9 \pm 2.2$; bPAB, $12.6 \pm 3.2$; $P=\mathrm{NS}$ ) and pre-Fontan (Norwood, $10.4 \pm 1.5$; bPAB, $10.5 \pm 2.1 ; P=\mathrm{NS})$ catheterizations. Mean pressure in the superior cavopulmonary connection before Fontan was similar as well (Norwood, $12.0 \pm 2.1$; bPAB, $12.1 \pm 2.2$; $P=$ NS). No patients in either group were excluded from candidacy for Fontan based on hemodynamic assessments of the PAs at the pre-Fontan catheterization.

\section{DISCUSSION}

This study evaluates the impact of bPAB placement on subsequent pulmonary arterial growth and the need for interventions. We have shown that patients undergoing bPAB placement require early and repeated operative and catheter-based interventions after bPAB removal. This finding is consistent with the limited data currently available. ${ }^{3,6}$

Pulmonary arterial banding induces regional inflammation within the vascular wall and ischemic injury resulting in the loss of cells in the media. ${ }^{2,4}$ Changes in pulmonary vascular wall morphology are present within 2 weeks, but fibrosis occurs later. ${ }^{4}$ Although the traditional use of the PA band on the pulmonary trunk is associated with the need for pulmonary arterioplasty at the time of debanding, repair of the pulmonary trunk has better outcomes

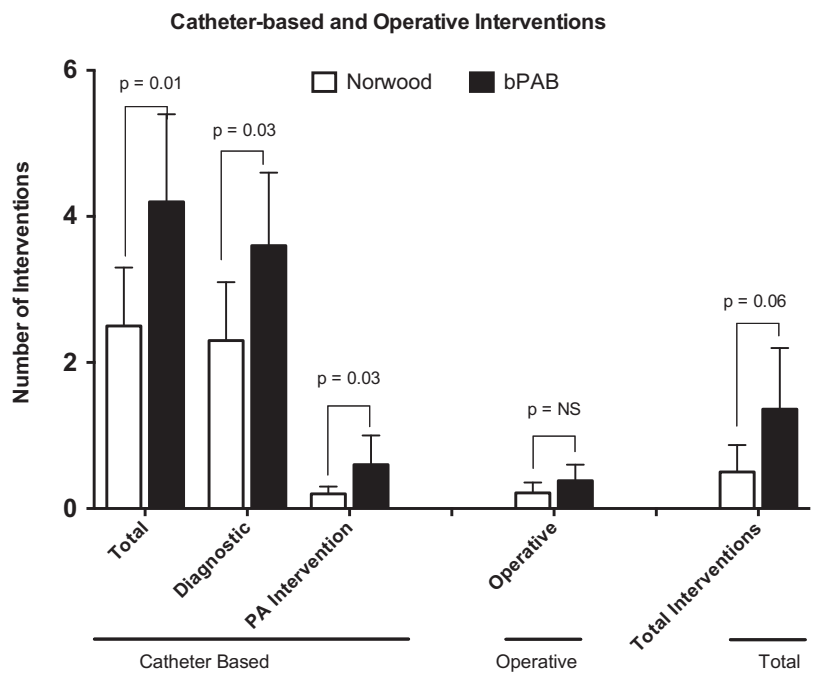

FIGURE 1. The mean number of catheterizations and operative interventions on the pulmonary arteries performed in the Norwood group (white columns) and the bilateral pulmonary arterial banding (bPAB) group (black columns). $95 \%$ confidence intervals of the means are illustrated by error bars. $P A$, Pulmonary artery. 


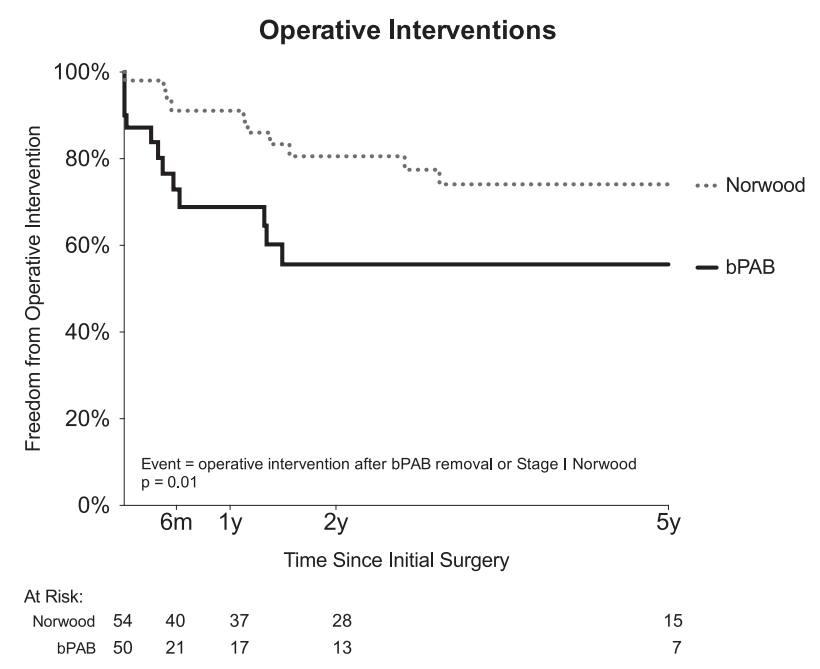

A

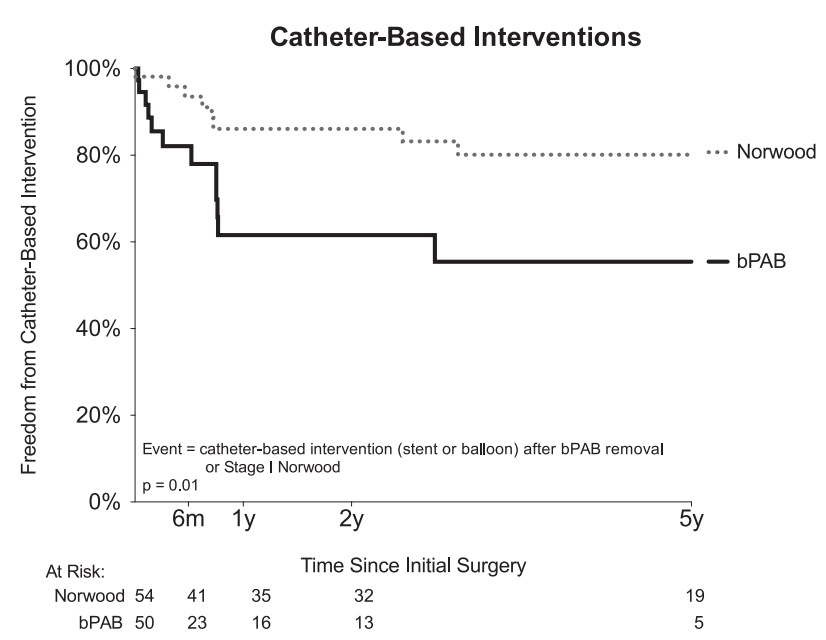

B

FIGURE 2. Five-year Kaplan-Meier survival estimates of freedom from operative intervention (A) and catheter-based interventions (B) on the pulmonary arteries.

than repairs of similar lesions on the more distal branch PAs. ${ }^{9}$ Whether the vascular damage inherent to pulmonary arterial banding has long-term negative effects on branch PAs has been only minimally investigated. ${ }^{3,10}$

In a study of patients undergoing hybrid stage 1 procedures, Baba and colleagues ${ }^{3}$ have shown that patients undergoing hybrid palliation have an increased need for reintervention and a lower Nakata index. Whether this is primarily related to the $\mathrm{BPAB}$ or to technical issues at the comprehensive stage 2 procedure as the authors postulate is not clear. Our data confirm the increased need for pulmonary interventions after bPAB.

We did not find that the use of a comprehensive stage 2 palliation was associated with subsequent pulmonary artery interventions; this suggests that the long-term need for

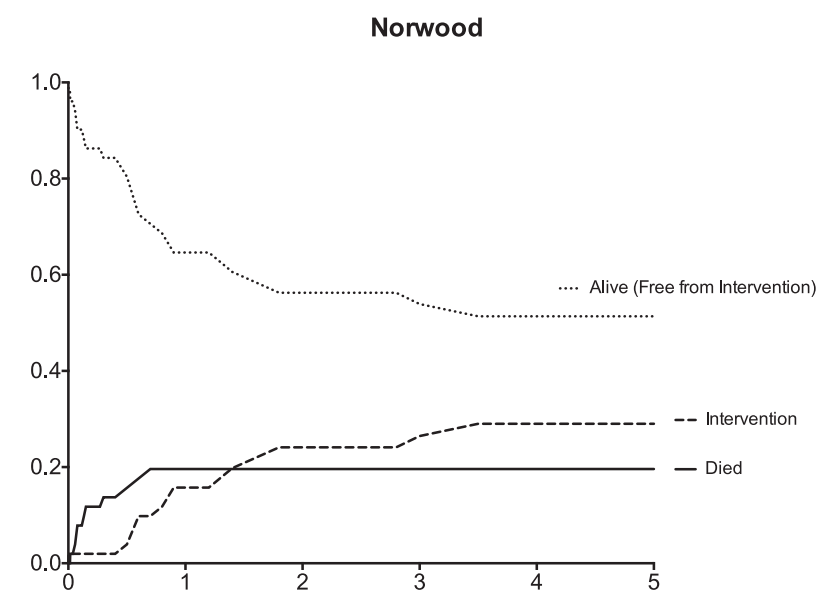

A

bPAB

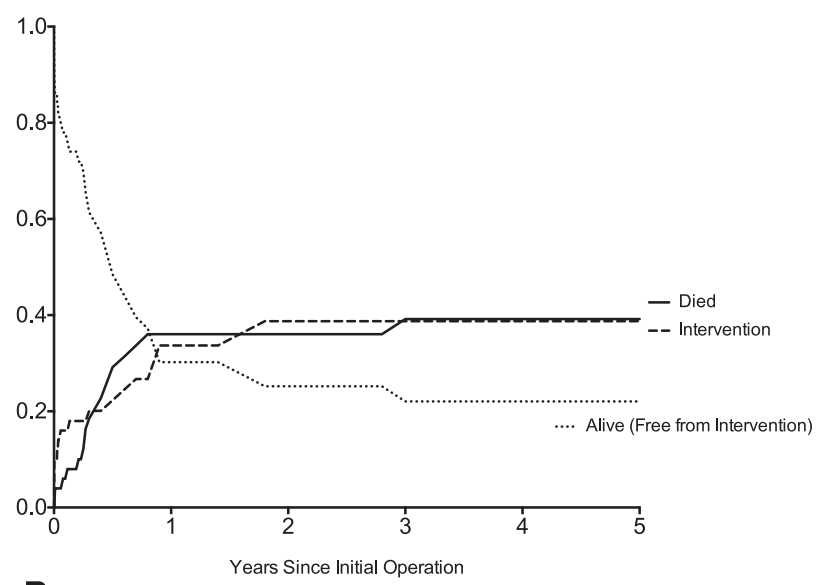

B

FIGURE 3. Competing risks analysis of patients after: A, Norwood operation; B, removal of bilateral pulmonary arterial banding (bPAB). Cumulative incidence of 3 competing outcomes is shown: death (solid black line), intervention (dashed black line), and alive without intervention (dotted black line). Comparison of cumulative incidence between groups: death $(P=.057)$, intervention $(P=.15)$.

reintervention is primarily related to the bPABs rather than the effects of the comprehensive stage 2 procedure. In addition, we found that smaller PA band diameter was associated with need for reintervention, and that PA band duration longer than 90 days was particularly detrimental to the branch PAs. Both these findings provide further evidence for the idea that it is the $\mathrm{BPAB}$ procedure itself rather than subsequent palliation that results in the high intervention rate.

Although the use of larger diameter bPABs might be reasonably expected to decrease the need for PA intervention, the fundamental goal of band placement is control of pulmonary blood flow. The margin of error for a band being either too tight or too loose is small in neonatal patients (particularly those with prematurity and low birth weight). 
Computer modeling suggests that banding to a 2-mm diameter is advantageous for systemic and cerebral blood flow, ${ }^{11}$ but this may increase the risk of pulmonary vascular problems. Initial banding must be directed at providing adequate systemic perfusion; however, it may be advantageous to err on the side of a slightly larger band in the early period to minimize the long-term risk to the PA.

Many of our patients have been managed with an initial bPAB placement for hemodynamic stabilization in the immediate postnatal period followed by a subsequent modified stage 1 Norwood procedure. This approach has been described by others. ${ }^{1}$ This limits the duration of bPAB compared with the strategy of comprehensive stage 2 . Given the high risk of PA intervention associated with longer duration of banding (especially $>90$ days), this may provide advantages compared with the typical hybrid path, particularly when the complicated nature of the comprehensive stage 2 procedure is included. ${ }^{12}$

Although a bPAB duration of more than 90 days carried the highest risk of reintervention, even patients with short durations had an incidence of multiple PA interventions exceeding $10 \%$. This suggests that stenosis requiring intervention may result from acute inflammation and surgical dissection rather than longer-term alterations in pulmonary arterial growth patterns.

We found that most preoperative factors were not significant predictors of the need for subsequent intervention. However, there was clearly a higher risk for subsequent PA interventions among patients who eventually underwent 2-ventricle repairs. One plausible explanation for this finding is that most single-ventricle patients underwent a hemi-Fontan procedure; this may have mitigated the risk of subsequent pulmonary arterial interventions. However, the hemi-Fontan primarily addresses right PA stenosis; however, the risk of additional interventions in 2-ventricle patients was particularly high in the left PA. This suggests that additional factors may be at work. Patients with an interrupted aortic arch were at particularly high risk; this may be related to distortion of the retroaortic region during the reconstructive surgery resulting in branch PA narrowing. In addition, the site of the left PA band is at the same location as the site found to be at risk of kinking in patients with redundant main PAs after tetralogy of Fallot repair. ${ }^{13}$ In the 2-ventricle patients initially managed with bPABs, this site may be vulnerable to small alterations in anatomy as would be seen with insertion of a RV-PA conduit or procedures directed at enlarging the pulmonary outflow. In contrast, the superior cavopulmonary connection used in the single-ventricle patients may address the right PA band site without altering the anatomy of the left PA site. These findings suggest the critical importance of preserving the normal course of the left PA in 2-ventricle repairs and performing concurrent left PA reconstruction where indicated. As additional patients undergo bPAB, further investigation into the outcomes among 2-ventricle patients may elucidate the mechanisms underlying the need for additional interventions.

It is reassuring that among all patients, pulmonary arterial size and growth rates were not lower among patients with bPAB placement. This suggests that the interventions are having the appropriate effect, at least in the midterm. Hemodynamics were also not affected significantly, and pulmonary arterial problems did not result in loss of Fontan candidacy.

Long-term successful Fontan palliation is dependent on a low pulmonary vascular resistance. Follow-up in this study is limited because of the recent increase in the use of bPAB. The long-term impact of multiple reinterventions on pulmonary arterial growth (both central and peripheral) is not clear. It remains to be seen whether long-term Fontan circuit pressures and ultimately clinical failure rates will be affected by the multiple pulmonary arterial interventions required to bring them to Fontan. Few data exist on the long-term effects on distal pulmonary architecture and this merits further follow-up.

\section{Limitations}

This was a retrospective review and the 2 cohorts differed in terms of preoperative risk factors. Although most of these risk factors would be expected to primarily affect mortality rather than the need for pulmonary arterial interventions, we cannot exclude the possibility that factors such as prematurity and low birth weight have long-term consequences for pulmonary arterial growth. However, in multivariable analysis, management strategy seemed to be the most important predictor of the need for PA interventions. Furthermore, analysis of risk factors within the bPAB group was unaffected by the lack of randomization. The more limited follow-up (with higher early mortality) among patients with $\mathrm{BPAB}$ may have reduced the negative impact of bPAB or obscured a difference in growth that would be apparent with longer follow-up in more patients.

\section{CONCLUSIONS}

The use of bPABs results in a significant increase in pulmonary arterial interventions. Patients with bPABs, especially those with smaller diameter bands and longer band placement, require a significant number of pulmonary arterial interventions. The use of bPAB in 2-ventricle patients may be particularly problematic. Despite these challenges, midterm PA size, hemodynamics, pulmonary vascular resistance, and Fontan candidacy seem to be maintained through multiple interventions. Long-term outcomes remain unclear.

\section{References}

1. Guleserian KJ, Barker GM, Sharma MS, Macaluso J, Huang R, Nugent AW, et al. Bilateral pulmonary artery banding for resuscitation in high-risk, single-ventricle 
neonates and infants: a single-center experience. J Thorac Cardiov Surg. 2013; 145:206-13; discussion 213-14.

2. Stark J, Berry CL, Silove ED. The evaluation of materials used for pulmonary artery banding: experimental study in piglets. Ann Thorac Surg. 1972; 13:163-9.

3. Baba K, Kotani Y, Chetan D, Chaturvedi RR, Lee K-J, Benson LN, et al. Hybrid versus Norwood strategies for single-ventricle palliation. Circulation. 2012;126: S123-31.

4. Cordell AR, Suh SH. The pulmonary artery lesion after banding: influence of differential materials. Ann Surg. 1974:179:805-12.

5. Galantowicz M, Cheatham JP, Phillips A, Cua CL, Hoffman TM, Hill SL, et al. Hybrid approach for hypoplastic left heart syndrome: intermediate results after the learning curve. Ann Thorac Surg. 2008;85:2063-70; discussion 2070-1.

6. Honjo O, Benson LN, Mewhort HE, Predescu D, Holtby H, Van Arsdell GS, et al. Clinical outcomes, program evolution, and pulmonary artery growth in single ventricle palliation using hybrid and Norwood palliative strategies. Ann Thorac Surg. 2009;87:1885-92; discussion 1892-3.

7. Pizarro C, Murdison KA. Off pump palliation for hypoplastic left heart syndrome: surgical approach. Semin Thorac Cardiovasc Surg Pediatr Card Surg Аппи. 2005;8:66-71.
8. Nedorost L, Uemura H, Furck A, Saeed I, Slavik Z, Kobr J, et al. Vascular histopathologic reaction to pulmonary artery banding in an in vivo growing porcine model. Pediatr Cardiol. 2013;34:1652-60.

9. Bacha EA, Kreutzer J. Comprehensive management of branch pulmonary artery stenosis. J Interv Cardiol. 2001;14:367-75.

10. Honjo O, Tran K-CD, Hua Z, Sapra P, Alghamdi AA, Russell JL, et al. Impact of evolving strategy on clinical outcomes and central pulmonary artery growth in patients with bilateral superior vena cava undergoing a bilateral bidirectional cavopulmonary shunt. J Thorac Cardiov Surg. 2010;140:522-8, 528.e1.

11. Baker CE, Corsini C, Cosentino D, Dubini G, Pennati G, Migliavacca F, et al., Modeling of Congenital Hearts Alliance (MOCHA) Investigators. Effects of pulmonary artery banding and retrograde aortic arch obstruction on the hybrid palliation of hypoplastic left heart syndrome. J Thorac Cardiov Surg. 2013;146: 1341-8.

12. Pizarro C, Derby CD, Baffa JM, Murdison KA, Radtke WA. Improving the outcome of high-risk neonates with hypoplastic left heart syndrome: hybrid procedure or conventional surgical palliation? Eur J Cardiothorac Surg. 2008;33: 613-8.

13. McElhinney DB, Parry AJ, Reddy VM, Hanley FL, Stanger P. Left pulmonary artery kinking caused by outflow tract dilatation after transannular patch repair of tetralogy of Fallot. Ann Thorac Surg. 1998;65:1120-6. 